\title{
Using Human-Centered Design to Develop a Program to Engage South African Men Living With HIV in Care and Treatment
}

Cal Bruns ${ }^{a}$

\section{Key Findings}

- HCD's structured, collaborative problem-solving process inspired the partners and allowed integration with multiple research methodologies. HCD excited seasoned HIV prevention and treatment veterans in the project's advisory group. The segmentation of at-risk male archetypes allowed men's attitudes, behaviors, and challenges to be seen through a human lens and informed HCD co-creation problem statements.

- HCD, paired with qualitative elicitation methods, allowed a deeper empathy with at-risk men and health professionals, ensuring the design of prototypes that addressed specific needs of men were desirable for them, as well as being feasible and viable for implementers.

- By integrating South African organizations, the Department of Health, and other funders into a project conceived with design thinking as an ingredient, our co-created innovations were primed for program integration and rapid scale-up with ongoing improvement through iteration.

\section{Key Implications}

Program managers and policy makers should consider using HCD approaches when designing or preparing to scale up interventions. In addition to informing program design, the implementation of HCD will foster stakeholder empathy, trust, and program "ownership" that will optimize acceptability, effectiveness, and sustainability of the intervention.
aMatchboxology, Cape Town, South Africa.

Correspondence to Cal Bruns (cal@matchboxology.com).

\section{ABSTRACT}

Background: Although HIV care is widely available in South Africa, men are less likely than women to know their HIV status, begin treatment upon diagnosis, and adhere to treatment. Men are also more likely to die from causes related to HIV compared to women. To overcome this inequity, tailored approaches designed with men's specific needs are required.

Methods: As part of the Testing and Treatment for Men project, a 3-year multicomponent, mixed-methods study that aimed to better understand young South African men's needs concerning HIV testing and treatment, we used human-centered design (HCD) methods to identify, develop, and pilot test a malefriendly peer-support intervention. We engaged key stakeholders in the development of several prototype interventions to improve men's engagement across the HIV cascade, one of which was selected for further development.

Results: Use of HCD methods, informed by the results of our team's prior qualitative and quantitative research, led to the development of Coach Mpilo, a peer-support intervention to engage and retain men living with HIV in South Africa in care and treatment. By designing with empathy for the lived experiences of these men, our intervention achieved the authenticity and credibility required to build trusting relationships in the affected communities. Preliminary results of Coach Mpilo have demonstrated a high level of acceptability by men living with HIV as well as key government and other implementing partners.

Conclusion: $\mathrm{HCD}$ as a critical ingredient became an integral and essential component in developing and field-testing the Coach Mpilo pilot. The key elements of our HCD approach that resulted in the successful generation of the Coach Mpilo pilot intervention and its implementation were understanding and addressing the specific issues identified by men living with HIV and leveraging newly created empathy with men as an approach to solving the issues collaboratively and innovatively.

\section{BACKGROUND}

D espite improvements in the availability of HIV testing, care, and treatment programs across subSaharan Africa, men's engagement across the HIV cascade is suboptimal. ${ }^{1-7}$ In South Africa, of the estimated 7.5 million adults ( 15 years and older) living with HIV in 2020 , approximately $36 \%$ were adult men. ${ }^{8}$ Compared to their female counterparts, South African men are less likely to know their HIV status, begin treatment upon 
diagnosis, or adhere to treatment. ${ }^{6-8}$ Consequently, South African men living with HIV are more likely to die of AIDS-related causes. ${ }^{9,10}$ To reach the global UNAIDS fast-track targets of $95-95-95$ by the end of 2030 - whereby $95 \%$ of people living with HIV know their status, $95 \%$ of those who know they are positive are on antiretroviral therapy (ART), and $95 \%$ of those on ART are virally suppressed- ${ }^{11}$ it is imperative that men are better engaged across the HIV care cascade. Effective strategies are needed to identify, engage, and retain men living with HIV in care to improve their health and to prevent ongoing transmission to their partners.

With funding from the Bill \& Melinda Gates Foundation, our consortium, including members with expertise in population health research and evaluation (Population Services International and Ipsos) and program design (Matchboxology), implemented Testing and Treatment for Men (TTM), a 3-year project aiming to increase uptake of HIV testing services by young South African men at high risk of acquiring HIV as well as initiation of ART for those newly diagnosed and those who had dropped out of care. A mixed-methods approach was used to understand men's decisions and behaviors related to HIV testing, prevention, and treatment and to identify different segments of young men to enable better-tailored interventions. A human-centered design (HCD) approach was used to explore strategies for reaching each segment with HIV prevention, testing, and treatment services more effectively.

HCD is a dynamic approach that engages endusers and key stakeholders to develop tailored, usable products, programs, or systems. ${ }^{12-14}$ For the past decade, there has been increasing adoption and integration of HCD practices in development initiatives, particularly in global health programming. ${ }^{15,16}$ Recently, the Design for Health community-launched by the Bill $\&$ Melinda Gates Foundation and the Center for Innovation and Impact in the U.S. Agency for International Development's (USAID) Bureau for Global Health-have defined the following 3 models by which design methods and mindsets can be applied in the development of global health solutions.

1. Spark: As a spark, design is used as an inspiration method to reframe the understanding of existing problems to make way for innovations. This might occur during structured brainstorming sessions focused on a clearly defined challenge to encourage teams to bring new ideas to the table.
2. As an ingredient, design can be used to improve an existing product or service by conducting rapid research to better understand the improvements needed and conducting a series of "trial and error" testing sessions to determine which ideas should be incorporated to improve the user experience of the existing product or service.

3. Using design in an end-to-end approach requires full adoption of design thinking and methods throughout solution development processes including conducting design research to reveal new user insights relevant to the challenge or need, codesigning solutions in partnership with key stakeholders, gathering feedback through prototyping and testing of ideas, and continued testing and refinement of the idea throughout implementation.

In this Supplemental issue of Global Health: Science and Practice, each case study will demonstrate the ways design was used either as a spark, ingredient, or an end-to-end approach to drive innovative ways of addressing complex global health challenges. In this article, we describe the process of using a design thinking approach as a critical ingredient for developing prototype interventions, followed by the selection of and pilot testing Coach Mpilo, a peer-support intervention designed to increase uptake of HIV testing, prevention, and linkage to care and treatment among young men in South Africa.

\section{METHODS}

The TTM project was conducted in 3 districts in South Africa with high HIV prevalence-Ehlanzeni and Gert Sibande (Mpumalanga Province) and Ugu (KwaZulu-Natal Province). We used an HCD approach to develop prototypes of interventions to achieve the aims of the TTM (i.e., increase HIV testing and uptake of ART among men who were newly diagnosed with HIV or who had previously dropped out of care). The design process was informed by input from an advisory group, as well as results from qualitative and quantitative studies led by members of our consortium. The design process was iterative (Figure 1). We briefly describe the components of the project.

\section{Advisory Group Consultation}

Advisory group (AG) members comprised national, provincial, and district Department of Health officials; national and local implementing partners; HIV-focused funders; representatives of normative bodies including the World Health Organization and UNAIDS; and civil society organizations. We

\section{A human- centered design approach was used to explore strategies for reaching each segment with HIV prevention, testing, and treatment services more effectively.}


FIGURE 1. Human-Centered Design Process Used to Develop Prototypes of Interventions to Increase HIV Testing and Update of Antiretroviral Therapy Among Men

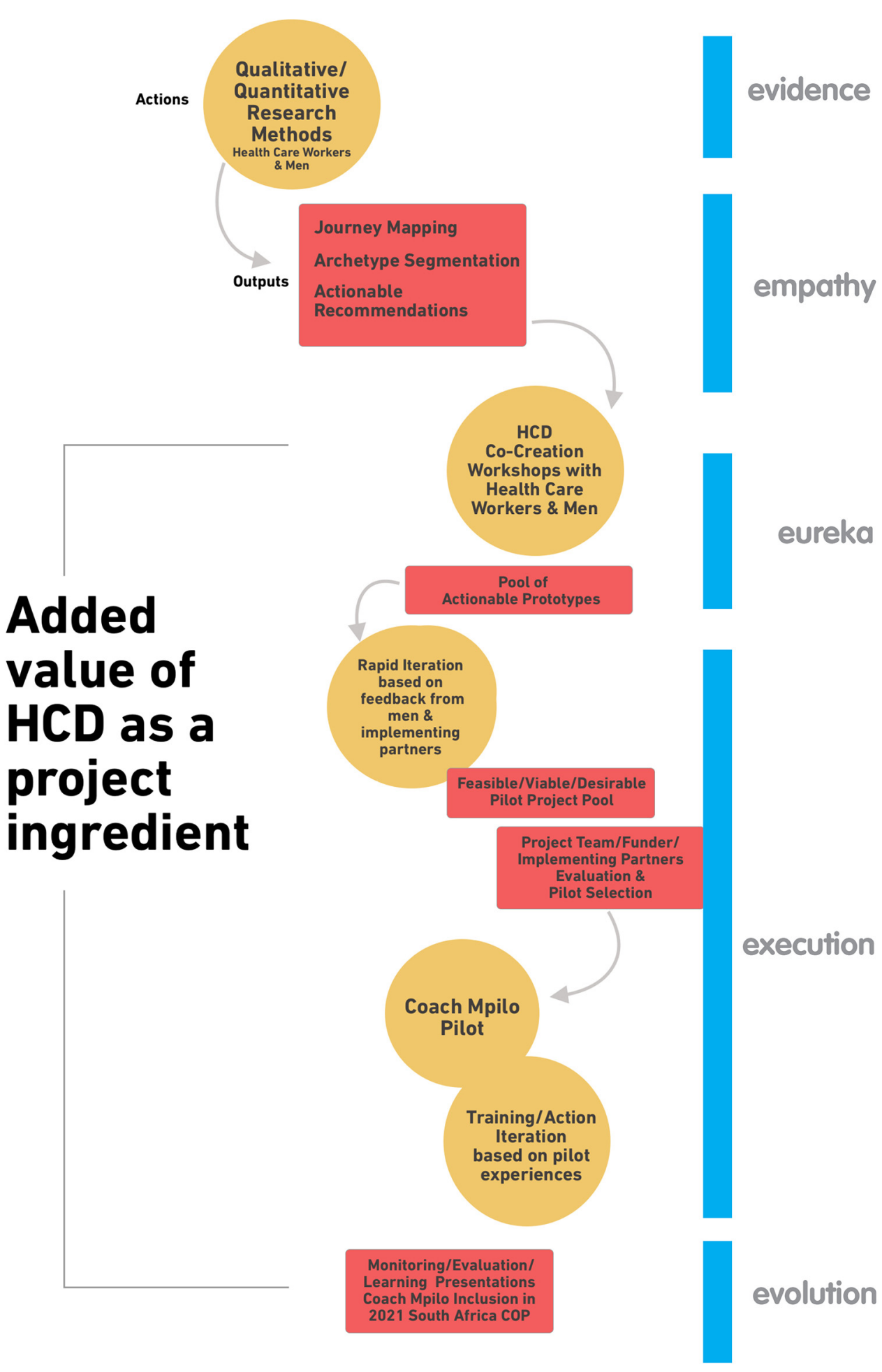


began with a "learning and listening workshop" augmented with one-on-one meetings with selected members. These were highly interactive opportunities to: (1) share learnings from previous successes and failures, (2) understand what AG members defined to be relevant academic or practical evidence based on lived experiences working with men, and (3) explore each participating organization's barriers, attitudes, motivations, and deliverables. Members were formally engaged at key design decision milestones across the project timeline.

\section{Qualitative Data Collection}

We recruited and enrolled health care providers and HIV-positive and HIV-negative men aged 25-34 years in high-HIV prevalence districts in Mpumalanga and KwaZulu-Natal Provinces to participate in qualitative data collection activities, including full-day ethnographic shadowing with men $(\mathrm{n}=18)$ and health care providers $(\mathrm{n}=4)$, as well as in-depth interviews with men $(n=58)$ and health care providers $(n=64)$. Ethnographic shadowing involved following and observing participants during their usual routines and asking them to interpret actions through informal interviews. All ethnographic work was conducted by male interviewers in the respondents' home languages.

\section{Quantitative Data Collection}

Details of the methods used have been previously presented. ${ }^{17}$ In brief, between October 2018 and
January 2019, a cross-sectional study was conducted in 8 district municipalities in Mpumalanga and KwaZulu-Natal Provinces including from 2,019 Black African men aged 20-34 years with less than a university-level education. Participants completed a survey of demographic characteristics, sexual behavior, engagement with HIV testing and treatment services, alcohol use, HIV knowledge, mental health, and attitudes to gender equity. The study was informed by the Theoretical Domain Framework ${ }^{18}$ and analyzed following a protocol described by Sgaier et al. ${ }^{19}$

\section{Prototype Design}

The results of the qualitative and quantitative studies were presented to the core group of partners and funders in February 2019, when data were synthesized to produce descriptions of each segment that incorporated the salient characteristics and attitudes, beliefs, and behaviors related to HIV testing and treatment (Figure 2). Based on insights from the segmentation, actionable prototype interventions were generated by core team members through the use of various HCD methods, ${ }^{13}$ including brainstorming, "how might we" questions, role-play, visualization, theme identification, and exercises (Table 1).

Three 3-day residential workshops were held ( 1 in Nelspruit, Mpumalanga, and 2 in Durban, KwaZulu-Natal), each including up to 32 participants representing a diverse mix of stakeholders

FIGURE 2. Characteristics of Male Archetypes Used in Segments That Incorporate Infection Attitudes, Beliefs, and Behaviors Related to HIV Testing and Treatment

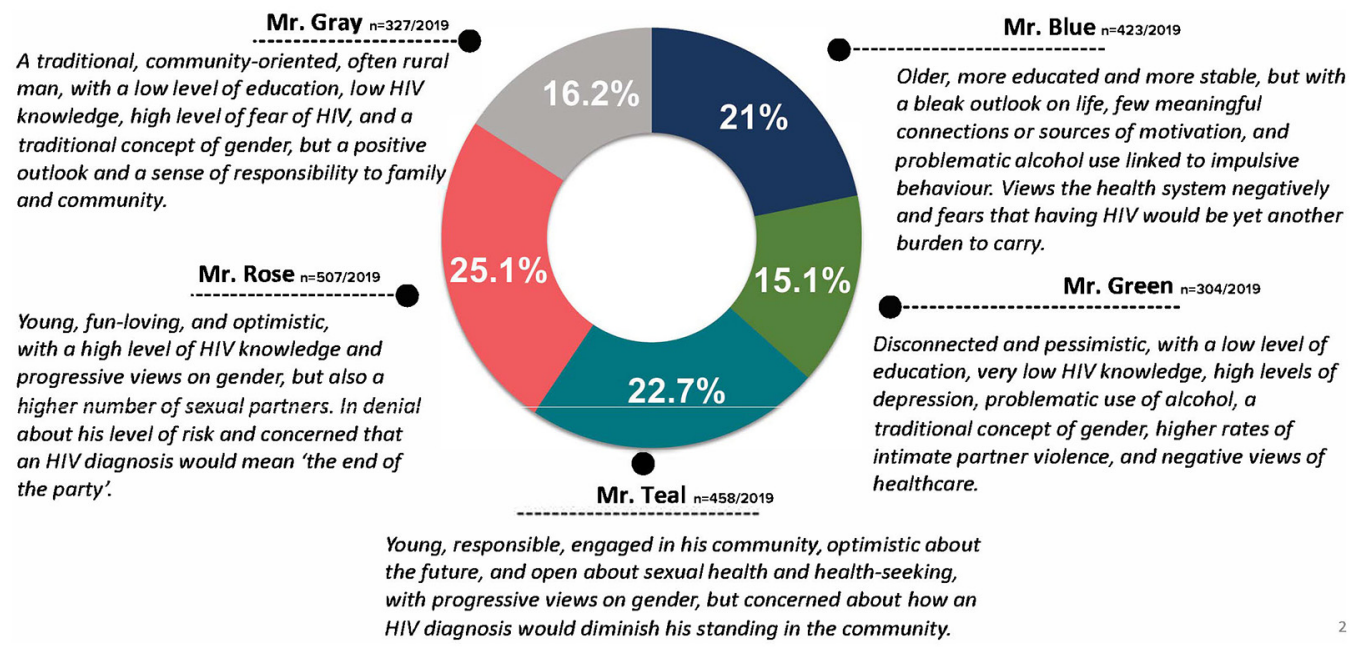


TABLE 1. HCD Activities to Support the Co-design of Program Prototypes

\begin{tabular}{|c|c|c|c|}
\hline Activity & Participants & Description & Contribution to Program Design \\
\hline Engage with AG & $\begin{array}{l}\text { National, provincial, and district DOH offi- } \\
\text { cials } \\
\text { National and local implementing partners } \\
\text { HIV-focused funders } \\
\text { Local experts }\end{array}$ & $\begin{array}{l}\text { Learning and listening workshop aug- } \\
\text { mented with one-on-one meetings with } \\
\text { selected members }\end{array}$ & $\begin{array}{l}\text { - Learnings shared from previous successes and fail- } \\
\text { ures } \\
\text { - Understand what AG members defined to be rele- } \\
\text { vant academic or practical evidence based on } \\
\text { lived experiences working with men } \\
\text { - Explore each participating organization's bar- } \\
\text { riers, attitudes, motivations, and deliverables } \\
\text { - The AG served as an expert resource with strate- } \\
\text { gic checkpoints to change direction in real-time }\end{array}$ \\
\hline $\begin{array}{l}\text { Video } \\
\text { ethnography }\end{array}$ & $\begin{array}{l}\mathrm{n}=18 \text { men; } \\
\mathrm{n}=4 \mathrm{HCWs}\end{array}$ & $\begin{array}{l}\text { 1-day video "follow-alongs" in } \\
\text { communities }\end{array}$ & $\begin{array}{l}\text { Increased empathy for men's self-reported interac- } \\
\text { tions with community members and the health care } \\
\text { system }\end{array}$ \\
\hline IDls & $\begin{array}{l}\mathrm{n}=58 \text { men; } \\
\mathrm{n}=64 \mathrm{HCW}\end{array}$ & $\begin{array}{l}\text { 2-hour IDIs in high HIV risk, hard-to- } \\
\text { reach communities } \\
\text { Journey mapping, a technique visualiz- } \\
\text { ing the health-seeking journey of at-risk } \\
\text { men to deepen empathy and inform } \\
\text { problem solving }\end{array}$ & $\begin{array}{l}\text { - Provided men space and time to express feelings } \\
\text { and insecurities that informed qualitative survey } \\
\text { design } \\
\text { - Highlighted logistical and emotional challenges of } \\
\text { at-risk men in South Africa, drawing attention to } \\
\text { friction points and barriers for confirmation via QS }\end{array}$ \\
\hline $\begin{array}{l}\text { Quantitative } \\
\text { surveys }\end{array}$ & $\begin{array}{l}\mathrm{N}=2,000 \text { men aged } 25-34 \text { years; high } \\
\text { school education or less }\end{array}$ & $\begin{array}{l}\text { 1-hour tablet-based surveys with random } \\
\text { sample of men across } 5 \text { districts in } \\
\text { KwaZulu-Natal and } 3 \text { districts in } \\
\text { Mpumalanga }\end{array}$ & $\begin{array}{l}\text { Generated statistically significant data points for ro- } \\
\text { bust segmentation analysis }\end{array}$ \\
\hline $\begin{array}{l}\text { Segmentation of } \\
\text { men }\end{array}$ & & $\begin{array}{l}\text { Cluster analysis via modeling, options } \\
\text { evaluation, and profiling based on } \\
\text { solutions }\end{array}$ & $\begin{array}{l}\text { Generated } 5 \text { distinct segments of men who gave new } \\
\text { insights to seasoned implementers, informed prob- } \\
\text { lem statements and recruitment into co-creation } \\
\text { process }\end{array}$ \\
\hline $\begin{array}{l}\text { How might we? } \\
\text { challenges }\end{array}$ & $\mathrm{n}=32$ workshop participants $\times 3$ workshops & $\begin{array}{l}6 \text { "How might we?" questions: } \\
\text { A positive, actionable question that } \\
\text { frames the challenge- a prompt used in } \\
\text { co-creation workshops to focus partici- } \\
\text { pants on a specific topic andgenerate } \\
\text { ideas }\end{array}$ & $\begin{array}{l}6 \text { "How Might We?" focused brainstorming to solve } \\
\text { very specific, granular issues facing } 2 \text { prioritized } \\
\text { segments deemed most likely to produce the greatest } \\
\text { impact across all } 5 \text { segments of men } \\
\text { Generated ideas for strategies that would be re- } \\
\text { sponsive to the needs of } 2 \text { prioritized segments } \\
\text { deemed most likely to produce the greatest impact } \\
\text { across all } 5 \text { segments of men }\end{array}$ \\
\hline $\begin{array}{l}\text { Experience } \\
\text { design }\end{array}$ & 32 workshop participants $\times 3$ workshops & $\begin{array}{l}\text { Focusing on the range of different health } \\
\text { care access and service delivery touch } \\
\text { points to reveal key gaps in quality ser- } \\
\text { vice delivery that might otherwise fall } \\
\text { through the cracks }\end{array}$ & $\begin{array}{l}\text { Bringing together men, HCW from clinics, and dis- } \\
\text { trict DOH staff as equal partners to design, rethink } \\
\text { assumptions, perceive impossibilities, and unlock } \\
\text { new ideas }\end{array}$ \\
\hline $\begin{array}{l}\text { Co-creation } \\
\text { prototyping }\end{array}$ & $\begin{array}{l}\mathrm{n}=32 \text { workshop participants } \times 3 \text { work- } \\
\text { shops; participants consisted of men from } 2 \\
\text { segments (recruited using an Ipsos-generat- } \\
\text { ed typing tool), HCWs, and DOH staff } \\
\text { Field testing storyboarded prototypes }\end{array}$ & $\begin{array}{l}\text { Co-designing a variety and range of } \\
\text { tangible engagement actions with users } \\
\text { and implementers via storyboarding, } \\
\text { which are believed to solve a specific } \\
\text { "How might we?" challenge }\end{array}$ & $\begin{array}{l}\text { Produced } 20 \text { diverse prototype concepts which were } \\
\text { refined to } 15 \text { simple-to-understand men's engage- } \\
\text { ment and service design proposals shared with men } \\
\text { in communities and implementation partners for fur- } \\
\text { ther evaluation }\end{array}$ \\
\hline
\end{tabular}


TABLE 1. Continued

\begin{tabular}{|c|c|c|}
\hline Participants & Description & Contribution to Program Design \\
\hline $\begin{array}{l}\text { Rapid prototype } \\
\text { feedback and } \\
\text { iteration }\end{array}$ & $\begin{array}{l}15 \text { visualizations of new service designs } \\
\text { and engagement initiatives were shared } \\
\text { with a random sample of men across the } \\
\text { project recruitment communities }\end{array}$ & $\begin{array}{l}\text { Informed iterative design alterations to several of the } \\
\text { prototypes, including changing the name of the } \\
\text { coaches to Coach Mpilo }\end{array}$ \\
\hline Prototype evaluation/prioritization & $\begin{array}{l}\text { Prioritization ranking analysis based on } \\
4 \text { criteria: feasible/viable/desirable/ } \\
\text { speed to results }\end{array}$ & $\begin{array}{l}4 \text { prototypes emerged as pilot finalists; Coach Mpilo } \\
\text { selected as the first fielded pilot }\end{array}$ \\
\hline
\end{tabular}

Abbreviations: AG, advisory group; DOH, Department of Health; HCD, human-centered design; IDI, in-depth interviews.

including male community participants, nurses, community leaders, and representatives from the provincial departments of health and implementing partners. Community participants were recruited by study staff members using a segmentation screening tool, developed by Ipsos, for "Mr. Green" and "Mr. Rose" types (Figure 2); potential participants were screened in short one-on-one interviews to ensure candidates had the capacity to express opinions and ideas within a workshop setting. Local clinic nurses and community leaders, district and provincial department of health officials, and AG members were also invited to participate in these workshops. Activities were organized around Matchboxology's e5 HCD process (Figure 3), designing and calibrating solutions that are responsive to the needs of the enduser and focused on addressing the various challenges that emerged in qualitative interviews with men representing the archetypes represented by "Mr. Green" and "Mr. Rose" (Figure 2).

\section{RESULTS}

\section{Qualitative and Quantitative Studies}

Qualitative research revealed several key barriers and challenges, most significantly that: men are afraid, not stubborn or indifferent; they have no one they trust or feel safe to talk to; they associate HIV testing and treatment initiation with loss, not gain; and they anticipate a negative experience in the clinic and by others following disclosure of their HIV status. The quantitative segmentation study produced 5 subgroups or segments of men, based on their attitudes, beliefs, behaviors, and needs related to HIV testing and treatment (described in depth in Bell et al). ${ }^{17}$

\section{PROTOTYPE DESIGN ACTIVITIES}

The AG recommended further development of prototype interventions focused on 2 of the 5 segments that were deemed the largest and most challenging:

"Mr. Green" and "Mr. Rose" (Figure 2).

Workshop participants generated more than 20 solution concepts, converging on 4 broad themes that revealed the following needs:

- "Flip the script" on ART: HIV treatment can trigger negative emotional responses. We need to change those so that men can feel good about being on treatment. Example: Move from a daily reminder that "I've lost control" to a daily reminder that "I'm in charge."

- Make HIV a collective challenge: Many men feel that having HIV is treated as a personal failure rather than a public health problem and that they are blamed and shamed rather than being supported. In reality, the strongest predictor of a man's HIV risk is not his behavior but where he lives. HIV isn't a personal failure, it's a community challenge.

- Help men feel they are not alone. Treatment leaves many men feeling alone, afraid, and ashamed. Many men feel there can be no good life after an HIV diagnosis. But men also said they could accept advice and support from a man who is living with HIV and doing well.

- Make the clinic a more familiar and welcoming space.

In selecting among possible solutions to pilot, we selected Coach Mpilo (Mpilo means health in Zulu and is a play on the English word pill), as it responded to all of these identified needs. The prototype was fully developed in collaboration with men and other stakeholders. Details of the program may be found elsewhere. ${ }^{20}$ In brief, Coach Mpilo is a peer-support model that recruits and employs men living with HIV who are stable on ART as coaches of newly diagnosed men and men lost to follow-up (Figure 4). It was designed to resonate with men in several ways including

\section{Qualitative research revealed several key barriers and challenges such as men feel they have no one they trust or feel safe to talk to and they associate HIV testing and treatment initiation with loss, not gain.}


FIGURE 3. Matchboxology's 5-Step Human-Centered Design Process

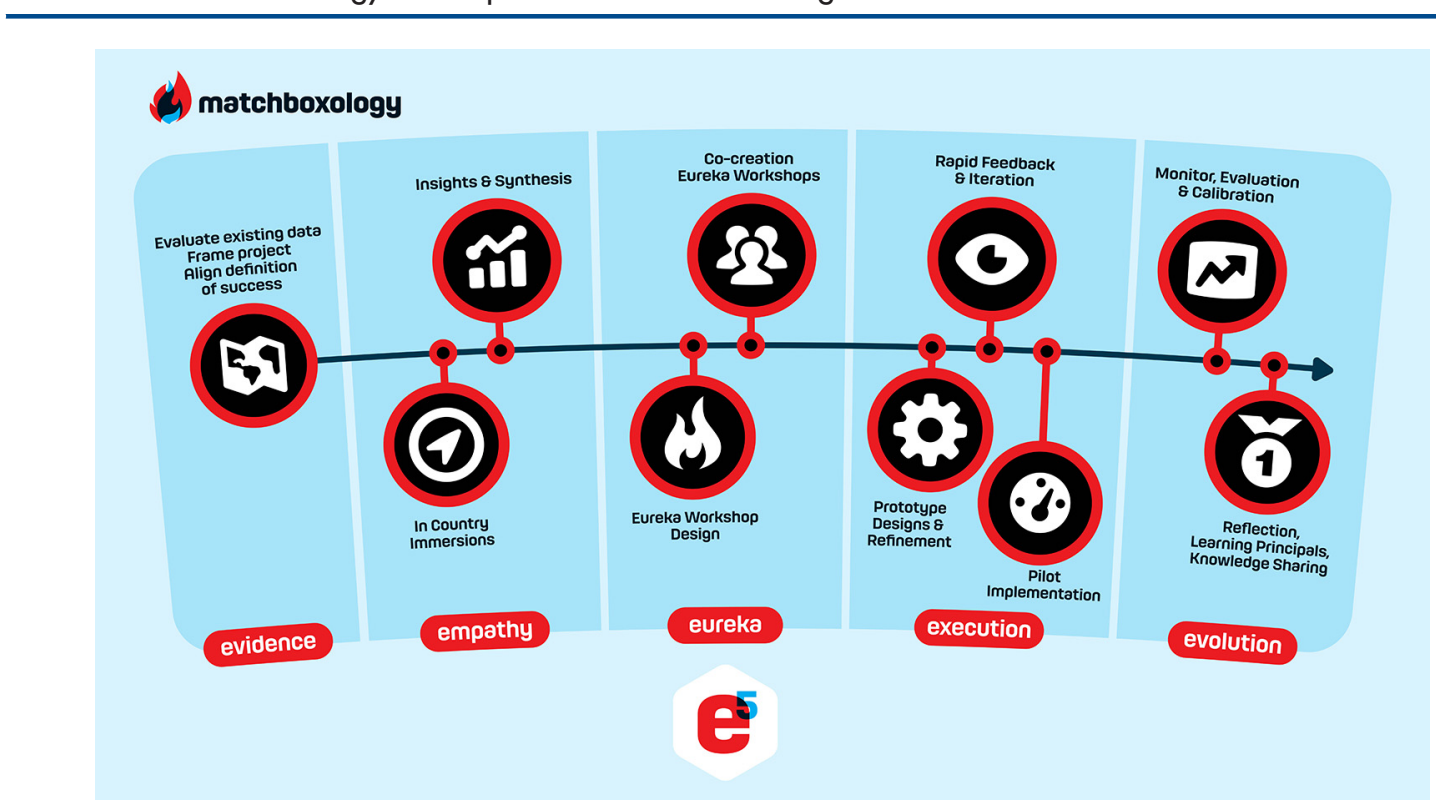

FIGURE 4. Coach Mpilo Program Conceptual Framework
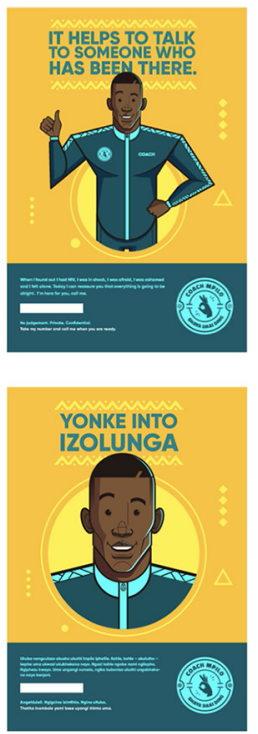

Abbreviation: ART, antiretroviral therapy.

\section{Program Components}

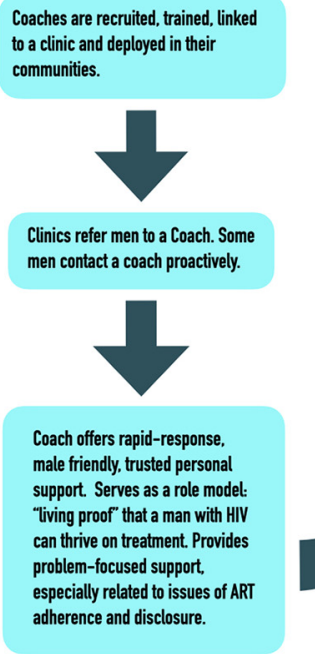

Mediators

Outcomes

\begin{tabular}{|l|l|}
$\begin{array}{l}\text { Knowledge and } \\
\text { understanding of } \\
\text { HIV \& ART. }\end{array}$ & $\begin{array}{l}\text { Increased uptake of ART } \\
\text { following HIV diagnosis or } \\
\text { re-initiation following } \\
\text { disengagement } \\
\text { from care. }\end{array}$ \\
\hline $\begin{array}{l}\text { Social Support. } \\
\text { Coping and } \\
\text { problem-solving skills. }\end{array}$ & \begin{tabular}{l} 
Improved ART adherence. \\
\hline Stigma.
\end{tabular} \\
\hline
\end{tabular}

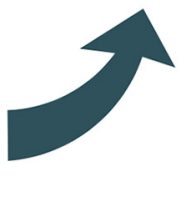

a

following HIV diagnosis or

Improved ART adherence.

Sustained engagement in

HIV care and treatment. breaking the isolation and paralysis that many men feel at diagnosis, giving men someone they can relate to and feel safe talking to, giving men "living proof" that a man can have HIV and live a normal life, supporting men to reimagine a positive future, and helping the coaches to reframe and reclaim their own identities. In addition to supporting men living with HIV to stay engaged 
TABLE 2. Additional Key Benefits Leveraged by Coach Mpilo

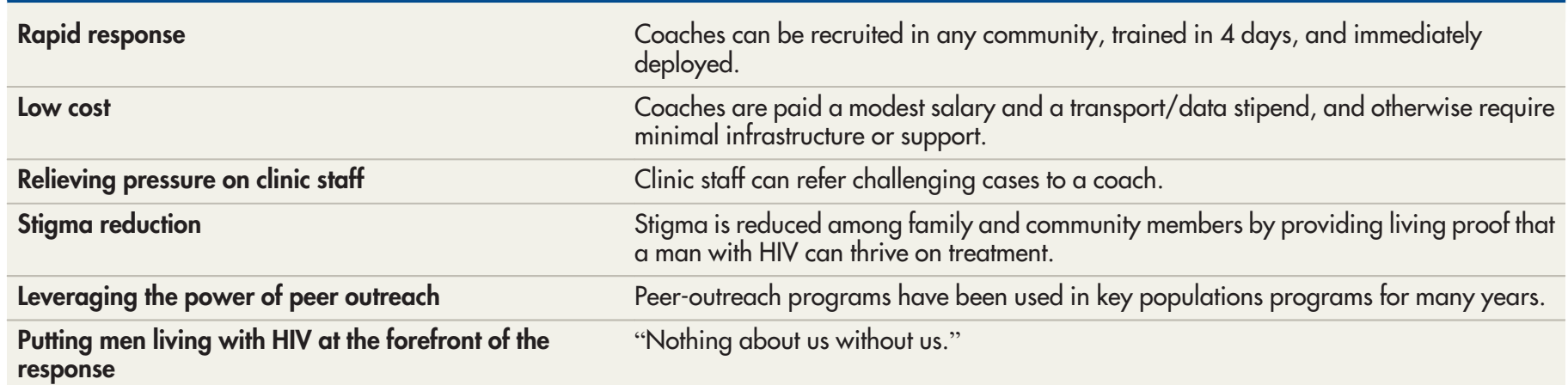

in care and treatment, Coach Mpilo was also designed to leverage other key benefits (Table 2). Figure 4 provides an overview of the Coach Mpilo intervention and how it is designed to work.

Since March 2020, the Coach Mpilo program has been implemented in Ehlanzeni and Gert Sibande Districts, Mpumalanga Province, and Ugu District, KwaZulu-Natal Province and has employed 120 coaches and reached over 3,700 men living with HIV. Preliminary data indicate that more than $90 \%$ of men are linked or returned to care within the first month of support and remain on treatment thereafter. HCD-driven piloting and rapid field iteration allowed course corrections to tailor the final prototype. The program has been met with a high level of acceptability by men, as well as key government, implementing, and funding partners. Coach Mpilo has been integrated by 4 implementing partners-Anova Health Institute, Aurum Institute, Centre for Communication Impact, and Wits Reproductive Health and HIV Institute-into current programming. Coach Mpilo has now been included in USAID's 2021 country operating plan.

\section{DISCUSSION}

By integrating HCD principles as a key ingredient during the development, implementation, and evaluation of the Coach Mpilo pilot program, we found that an HCD approach ensured empathy in understanding how men living with HIV in South Africa experience the world and keeping them at the center of problem statements and engagement design processes. This depth of empathy also empowered decision makers in making informed decisions that would achieve better outcomes and allowed for robust, rapid evaluations of prototypes that emerged from the HCD methodologies because all parties had considered issues of desirability, feasibility, and viability from the beginning of the endeavor. The AG served as an expert resource with strategic checkpoints to change direction in real-time. The team incorporated inputs provided by the AG and other stakeholders while being mindful of potential implementation barriers and tailoring project components accordingly. Ethnographic and qualitative studies were a critical part of the HCD process as the results of those studies directly informed the co-creation sessions and prototype iterations.

By applying the HCD approach, we developed an intervention to retain men living with HIV in South Africa in care and treatment services. It was clear from this process that:

- HCD methods have the potential to create prototypes for programs that are highly desirable, feasible, and viable

- Applying HCD philosophies throughout stakeholder engagement helps to ensure both greater empathy among all parties and the "ownership" of health programs that will contribute strongly to their success and sustainability

The HCD process enabled our team to identify that the fundamental and unique value of the coach is that of trust. This trust was consistently protected within our design by the requirement that coaches come from outside of a clinic system that men have grown to distrust. Each coach had credibility because he is someone who has "been there with the virus"; this was articulated through the HCD process as the most valuable proposition in the prototype. Being a coach has also changed the self-esteem and community respect for the men who adopt this role. In addition, Coach Mpilo addresses a critical national issue of unemployment, giving work to men in a country with an unemployment rate of more than $30 \%$.

\section{Preliminary data on the Coach Mpilo program indicate that more than $90 \%$ of men are linked or returned to care within the first month of support and remain on treatment thereafter.}

The HCD process enabled our team to identify that the fundamental and unique value of the coach is that of trust. 
Quality control throughout each aspect of the design process, data collection, and program implementation was critical to success. Maintaining prototype design fidelity required that coach positions be filled only by men living with HIV. By designing with empathy for the lived experiences of these men, our intervention achieved the authenticity and credibility required to build trusting relationships in the affected communities. HCD workshops stressed that coaches must be mentors who have "lived the journey"-a practice that resulted in improved engagement in retention in HIV care and treatment services. The performance of the coaches in the pilot revealed the impact of reducing stigma, which potentially accelerated ART uptake and adherence.

The key to the success of the design process and program pilot of Coach Mpilo was the influence of an "HCD as ingredient" approach on the project philosophy and its application in the development of the intervention. The success of future iterations of Coach Mpilo will require applying HCD principles to the implementation and scaleup of the intervention. This will help to ensure that stakeholder empathy, trust, and program "ownership" are integrated into all aspects of program design and rollout, driving toward greater acceptability, success, and sustainability of the intervention.

"Mission creep" presents one of the most significant risks for scaling up Coach Mpilo. Funders may look for ways to leverage investments in Coach Mpilo to gather additional health burden data or perform other functions in their communities (e.g., TB or gender-based violence education). The coach's value to the community and to the individual is as a trusted advisor independent from the traditional health care system, and adding roles beyond this core competency risks compromising program impact and data quality. Plans for scale-up of Coach Mpilo will thus need to consider several key issues and potential challenges, including program ownership and accountability, more rigorous evaluation approaches, and long-term sustainability and commitments for funding.

\section{CONCLUSION}

Deployed as an ingredient in this and similar projects, HCD can help to avoid errors based on topdown assumptions and biases and incorporate the lived experiences and perspectives of men living with HIV, as well as health care ecosystem expertise, into producing desirable and workable solutions that reduce the risk of failure when piloted.
Ultimately, our process generated deeply empathetic and highly pragmatic solutions by and for men living with HIV that clearly addressed their issues related to linkage to and retention in HIV care and treatment services. Every man's life changed is a story, not just a statistic. By engaging key stakeholders in the design of our interventions, HCD helped to produce outcomes that matter.

We hope that the Coach Mpilo pilot can inform the integration of HCD that addresses health programs and interventions across diverse populations and health issues.

Acknowledgments: The author wishes to thank the following individuals who played key roles: project concept and management: Nina Hasen, Shawn Malone, Kristen Little (Population Services International), Sunny Sharma (Ipsos Mori), and Paris Pitsillides (Matchboxology). Qualitative/ quantitative research design, methodology, analysis, and segmentation: Sunny Sharma, James Bell, Melissa Levy, and Jemma Reast (Ipsos Mori Research). HCD field workshop design and facilitation: Cal Bruns, Paris Pitsillides, Jason Coetzee, Thulani Grenville Grey, and Silver Shabalala (Matchboxology). HCD pilot creative direction and management: Paris Pitsillides, Thulani Grenville Grey, Silver Shabalala, Melusi Tshabalala, and Cal Bruns (Matchboxology). Writing, review, and editing: Agnès Fiamma Papone, Lisa M. Butler, and Greg Szekeres.

Funding: The Bill \& Melinda Gates Foundation (funding number INV009242) provided funding for the research but did not have any additional role in the study design, data collection and analysis, decision to publish, or preparation of the manuscript.

Competing interests: The author works for Matchboxology, which is a human-centered design consultancy that conducts research on behalf of other funders and commercial companies, including in the field of HIV.

\section{REFERENCES}

1. Grimsrud A, Ameyan W, Ayieko J, Shewchuk T. Shiffing the narrative: from "the missing men" to "we are missing the men". J Int AIDS Soc. 2020;23 Suppl 2(Suppl 2):e25526. CrossRef. Medline

2. Hamilton A, Thompson N, Choko AT, et al. HIV self-testing uptake and intervention strategies among men in sub-Saharan Africa: a systematic review. Front Public Health. $2021 ; 9: 594298$. CrossRef. Medline

3. Green D, Tordoff DM, Kharono B, et al. Evidence of sociodemographic heterogeneity across the HIV treatment cascade and progress towards 90-90-90 in sub-Saharan Africa-a systematic review and meta-analysis. J Int AIDS Soc. 2020;23(3):e25470. CrossRef. Medline

4. Heestermans T, Browne JL, Aitken SC, Vervoort SC, KlipsteinGrobusch K. Determinants of adherence to antiretroviral therapy among HIV-positive adults in sub-Saharan Africa: a systematic review. BMJ Glob Health. 2016;1 (4):e000125. CrossRef. Medline

5. Hlongwa M, Mashamba-Thompson T, Makhunga S, Hlongwana K. Barriers to HIV testing uptake among men in sub-Saharan Africa: a scoping review. Afr J AIDS Res. 2020;19(1):13-23. CrossRef. Medline

6. Tsai AC, Siedner MJ. The missing men: HIV treatment scale-up and life expectancy in sub-Saharan Africa. PLoS Med. 2015;12(11): e1001906. CrossRef. Medline

7. UNAIDS. A Snapshot of Men and HIV in South Africa. UNAIDS; 2017. Accessed August 31, 2021. https://www.unaids.org/sites/ default/files/snapshot-men-hiv-south-africa_en.pdf 
8. Country factsheets: South Africa. UNAIDS. https://www.unaids. org/en/regionscountries/countries/southafrica

9. Bor J, Rosen S, Chimbindi N, et al. Mass HIV treatment and sex disparities in life expectancy: demographic surveillance in rural South Africa. PLoS Med. 2015;12(11):e1001905. CrossRef. Medline

10. Cornell $M$, Johnson LF, Wood $R$, et al. Twelve-year mortality in adults initiating antiretroviral therapy in South Africa. J Int AIDS Soc. 2017;20(1):21902. CrossRef. Medline

11. UNAIDS. Fast-Track: Ending the AIDS Epidemic by 2030. UNAIDS 2014. Accessed August 31, 2021. https://www.unaids.org/sites/ default/files/media_asset/JC2686_WAD2014report_en.pdf

12. Bannon $\amalg$, Ehn P. Design: design matters in participatory design. In: Simonsen J, Robertson T, eds. Routledge International Handbook of Participatory Design. Routledge; 2013:37-63.

13. Lewrick M, Link P, Leifer $\sqcup$. The Design Thinking Toolbox: A Guide to Mastering the Most Popular and Valuable Innovation Methods. John Wiley \& Sons, Inc.; 2020.

14. Brown T, Wyatt J. Design thinking for social innovation. Development Outreach. 2010;12(1):29-43. CrossRef

15. Bazzano AN, Martin J, Hicks E, Faughnan M, Murphy L. Humancentred design in global health: a scoping review of applications and contexts. PLoS One. 2017;12(11):e0186744. CrossRef. Medline

16. Beres LK, Simbeza S, Holmes CB, et al. Human-centered design lessons for implementation science: improving the implementation of a patient-centered care intervention. J Acquir Immune Defic Syndr. 2019;82(3):S230-S243. CrossRef. Medline

17. Bell J, Sharma S, Malone S, et al. Targeting interventions for HIV testing and treatment uptake: an attitudinal and behavioural segmentation of men aged 20-34 in KwaZulu-Natal and Mpumalanga, South Africa. PLoS One. 2021;16(3):e0247483. CrossRef. Medline

18. Cane J, O'Connor D, Michie S. Validation of the theoretical domains framework for use in behaviour change and implementation research. Implement Sci. 2012;7(1):37. CrossRef. Medline

19. Sgaier SK, Eletskaya M, Engl E, et al. A case study for a psychographic-behavioral segmentation approach for targeted demand generation in voluntary medical male circumcision. elife. 2017;6:e25923. CrossRef. Medline

20. A community-based peer-support intervention to improve men's linkage to and early retention in HIV treatment. MenStar Coalition. Accessed August 31 , 2021. hitps://menstarcoalition.org/notlinked/coach-mpilo/

\section{Peer Reviewed}

Received: April 16, 2021; Accepted: August 26, 2021.

Cite this article as: Bruns C. Using human-centered design to develop a program to engage South African men living with HIV in care and treatment. Glob Health Sci Pract. 2021 ;9(Suppl 2):S234-S243. https://doi.org/10.9745/GHSP-D-21-00239

(C) Bruns. This is an open-access article distributed under the terms of the Creative Commons Attribution 4.0 International License (CC BY 4.0), which permits unrestricted use, distribution, and reproduction in any medium, provided the original author and source are properly cited. To view a copy of the license, visit https://creativecommons.org/licenses/by/4.0/. When linking to this article, please use the following permanent link: https://doi. org/10.9745/GHSP-D-21-00239 